\title{
EDITORIAL
}

\section{The challenges of caring for twins discordant for anomalies}

Journal of Perinatology (2009) 29, 653-654; doi:10.1038/jp.2009.131

Congenital anomalies in twins occur nearly twice as often as in singletons. Moreover, the prevalence of congenital anomalies in monochorionic twins is nearly twice that of dichorionic pairs. ${ }^{1}$ This is true of all types of major structural anomalies, but not chromosomal aneuploidy. In singletons, anomalies are managed with regard to the best outcome possible for that fetus, in harmony with the patient's wishes. In the setting of twins, discordant anomalies considerably complicate the issues. An anomalous fetus is subject to overall greater risk of morbidity and mortality, including intrauterine growth restriction, intrauterine fetal demise and the need for preterm delivery. When the affected twin experiences complications necessitating delivery, the difficult decision of whether or not to sacrifice that twin or deliver its co-twin prematurely has to be made. Taking a step back, however, it is helpful to first consider whether the placentation of the affected pair is dichorionic or monochorionic.

In a dichorionic twin pair, a structurally anomalous twin does have a greater incidence of aneuploidy when compared with its cotwin. Moreover, beyond structural anomalies, one placenta may have poor implantation or suffer vascular insufficiency, leading to growth restriction and discordance in size; far less commonly a discordant viral infection to one twin is vertically transmitted. As each twin has an independent circulatory system without inter-twin connections, patients may opt to selectively terminate, or reduce, the affected twin using ultrasound-guided procedures, such as intracardiac $\mathrm{KCl}$, which can be achieved with a narrow gauge spinal needle and a relatively low complication rate, where legal, in any trimester. ${ }^{2}$

In contrast, in a structurally or size discordant monochorionic pair, discordant aneuploidy is exceedingly rare (though not impossible). As noted above, structural anomalies are twice that expected in dichorionic pairs, given the monozygozity. Other discordant complications in monochorionic twins, such as unequal placental sharing, selective intrauterine growth restriction, twin-to-twin transfusion syndrome and twin reversed arterial perfusion sequence, are linked to the inter-twin vascular connections that all monochorionic twin pairs have, ${ }^{3,4}$ As the circulations are not independent, selective termination cannot be achieved with injection of medical therapeutics because of the effect on the co-twin. More invasive and higher-risk procedures such as cord coagulation, and now the more commonly carried out radio frequency ablation of the affected twin's cord, are necessary to reduce one twin without causing morbidity in it's co-twin. ${ }^{5-7}$
In this issue of the Journal of Perinatology, Malhotra et al. explore the problem of discordant anomalies in a twin pair. Modern prenatal diagnostics are making such scenarios more commonplace. The discovery of one affected fetus in a twin pair leads to complex counseling and difficult decision making, yet time and again, we have found it, at our center, to be the information that patients overwhelmingly desire. Cardiac defects remain the most common of all structural fetal anomalies, and the authors review their experience with six twin pregnancies discordant for major congenital cardiac disease and the options that were made available to them. These included termination of the entire pregnancy, selective termination of the affected twin and expectant management. The authors reviewed the factors involved in each twin pair and formulated an approach to decision making in such cases. An important consideration not to be overlooked was the availability of potential 'comfort care' for the affected fetus versus planning for post-natal treatment.

The six selected cases in effect represent some of the key issues of importance in discordant twins. As would be expected, four of the six were monochorionic twins, making selective termination significantly more challenging. Two patients in Malhotra's study stated that they would have pursued selective termination, but decided against it because of the potential risks of preterm labor and/or adverse neurological outcomes in the surviving twin. Indeed, a small risk of adverse neuromorbidity in the surviving co-twin has been seen with some of the occlusive devices. Operator experience and procedure availability are major obstacles for patients interested in cord occlusion of the affected twin in a monochorionic pair. Owing to the larger gauge devices and differing technology used, these procedures carry a potentially greater risk for procedure-related loss and/or preterm labor, when compared with selective termination in dichorionic twins. Furthermore, only minimal long-term neurological follow up is currently available for surviving twins after co-twin cord coagulation. ${ }^{5}$ Radio frequency ablation has been used with great success in cases of twin reversed arterial perfusion sequence, where the acardiac mass has no placental share. ${ }^{7}$ Although cord occlusion by radio frequency ablation (which now requires only a $17-\mathrm{G}$ device) is quickly becoming the favored mechanism for selective termination in anomalous or discordant monochorionic twins, the potential neuromorbidity (whether used in the setting of two beating hearts or one), has not yet been studied.

To help patients address this, fetal magnetic resonance imaging of the brain may be carried out after cord occlusion to interrogate 
for evidence of ischemic white matter damage. It has been well established that despite excellent fetal neurosonography, ultrasound is limited in its ability to diagnose ischemic injury, whereas magnetic resonance imaging excels at this and often adds to the sonographic findings. ${ }^{8}$ Unfortunately, long-term neurological outcome studies are needed to validate the sensitivity and specificity of fetal neuro-magnetic resonance image findings. Thus, the counseling for selective termination in monochorionic pregnancies remains quite complex, as is the access to a skilled referral center for procedures and specialized imaging.

Expectant management is a reasonable option for many cardiac lesions with currently available postnatal medical and surgical treatment capabilities. Whenever possible, patients should be counseled by a pediatric cardiologist regarding the specific lesion, potential treatment options and expected outcomes. If the pregnancy is continued, management and delivery is optimal at a center offering a fetal heart program with the established coordinated antenatal, intrapartum and postnatal cardiac care, as well as pediatric cardiac surgery. In addition, an important option for several of the patients in this report was the availability of 'comfort care' for their affected neonate, so that they could opt not to treat postnatally if so desired. As the authors point out, comfort care is not as widely available as one might hope - and is a critical and compassionate care component linking providers, grieving parents and sick neonates. Malhotra et al. again illustrate the importance of creating such multi-disciplinary care and policy in this study.

It should be noted that none of the cases in this report were offered in-utero treatment. In-utero treatment options for select lesions, such as stenotic valvular disease (leading to hypoplastic left heart syndrome), are being carried out on a limited basis in several select centers. ${ }^{9-12}$ These are highly specialized procedures, and outcomes have been variable. ${ }^{13,14}$ Experience in twin gestations, however, is essentially non-existent, and concerns about iatrogenic prematurity in this setting are quite high.

The authors conclude that optimal counseling requires sound clinical knowledge about the medical risks to the mother and her twins, and this does remain most imperative. Every effort should be made for access to specialized centers with skilled fetal intervention capabilities and fetal/pediatric cardiac programs. Studies of long-term outcomes after selective termination of a monochorionic twin are eagerly awaited, as are the expansion of compassionate care options for parents and neonates in this difficult position.

$$
\begin{array}{r}
\text { L Rand }^{1} \text { and AB Caughey } \\
{ }^{1} \text { Department of Obstetrics, Gynecology and Reproductive } \\
\text { Sciences, University of California, San Francisco, CA, USA } \\
\text { E-mail: randl@obgyn.ucsf.edu }
\end{array}
$$

\section{References}

1 Glinianaia SV, Rankin J, Wright C. Congenital anomalies in twins: a register-based study. Hum Reprod 2008; 23(6): 1306-1311.

2 Evans MI, Goldberg JD, Horenstein J, Wapner RJ, Ayoub MA, Stone J et al. Selective termination for structural, chromosomal, and mendelian anomalies: international experience. Am J Obstet Gynecol 1999; 181(4): 893-897.

3 Machin GA, Keith LG. An Atlas of Multiple Pregnancy: Biology and Pathology. Parthenon Publishing Group: New York, NY, 1999.

4 Fick AL, Feldstein VA, Norton ME, Wassel Fyr C, Caughey AB, Machin GA. Unequal placental sharing and birthweight discordance in monochorionic diamniotic twins. Am J Obstet Gynecol 2006; 195: 178-183.

5 Lewi L, Gratacos E, Ortibus E, Van Schoubroeck D, Carreras E, Higueras T et al. Pregnancy and infant outcome of 80 consecutive cord coagulations in complicated monochorionic multiple pregnancies. Am J Obstet Gynecol 2006; 194(3): 782-789.

6 Spadola AC, Simpson LL. Selective termination procedures in monochorionic pregnancies. Semin Perinatol 2005; 29(5): 330-337.

7 Lee H, Wagner AJ, Sy E, Ball R, Feldstein VA, Goldstein RB et al. Efficacy of radiofrequency ablation for twin reversed arterial perfusion sequence. Am J Obstet Gynecol 2007; 196: 459.e1-459.e4.

8 Jelin AC, Norton ME, Bartha AI, Fick AL, Glenn OA. Intracranial magnetic resonance imaging findings in the surviving fetus after spontaneous monochorionic co-twin demise. Am J Obstet Gynecol 2008; 199(4): 398.e1-398.e5.

9 Wilkins-Haug LE, Benson CB, Tworetzky W, Marshall AC, Jennings RW, Lock JE. In-utero intervention for hypoplastic left heart syndrome-a perinatologist's perspective. Ultrasound Obstet Gynecol 2005; 26(5): 481-486.

10 Tworetzky W, Wilkins-Haug L, Jennings RW, van der Velde ME, Marshall AC, Marx GR et al. Balloon dilation of severe aortic stenosis in the fetus: potential for prevention of hypoplastic left heart syndrome: candidate selection, technique, and results of successful intervention. Circulation 2004; 110(15): 2125-2131. Epub 2004 Oct 4.

11 Marshall AC, van der Velde ME, Tworetzky W, Gomez CA, Wilkins-Haug L, Benson CB et al. Creation of an atrial septal defect in utero for fetuses with hypoplastic left heart syndrome and intact or highly restrictive atrial septum. Circulation 2004; 110(3): 253-258. Epub 2004 Jun 28.

12 Wilkins-Haug LE, Tworetzky W, Benson CB, Marshall AC, Jennings RW, Lock JE. Factors affecting technical success of fetal aortic valve dilation. Ultrasound Obstet Gynecol 2006; 28(1): 47-52

13 Marshall AC, Tworetzky W, Bergersen L, McElhinney DB, Benson CB, Jennings RW, Wilkins-Haug LE, Marx GR, Lock JE. Aortic valvuloplasty in the fetus: technical characteristics of successful balloon dilation. J Pediatr 2005; 147(4): 535-539. 